\title{
Pulmonary Rehabilitation in the Management of Chronic Obstructive Pulmonary Disease among Asian Indians- Current Status and Moving Forward
}

Citation for published version (APA):

Bhadra, R., Bhattacharya, S., D'Souza, G. A., Schols, A. M. W. J., \& Sambashivaiah, S. (2021). Pulmonary Rehabilitation in the Management of Chronic Obstructive Pulmonary Disease among Asian Indians- Current Status and Moving Forward. Copd-Journal of Chronic Obstructive Pulmonary Disease, 18(4), 476-481. https://doi.org/10.1080/15412555.2021.1962267

Document status and date:

Published: 04/07/2021

DOI:

10.1080/15412555.2021.1962267

Document Version:

Publisher's PDF, also known as Version of record

Document license:

Taverne

Please check the document version of this publication:

- A submitted manuscript is the version of the article upon submission and before peer-review. There can be important differences between the submitted version and the official published version of record.

People interested in the research are advised to contact the author for the final version of the publication, or visit the DOI to the publisher's website.

- The final author version and the galley proof are versions of the publication after peer review.

- The final published version features the final layout of the paper including the volume, issue and page numbers.

Link to publication

\footnotetext{
General rights rights.

- You may freely distribute the URL identifying the publication in the public portal. please follow below link for the End User Agreement:

www.umlib.nl/taverne-license

Take down policy

If you believe that this document breaches copyright please contact us at:

repository@maastrichtuniversity.nl

providing details and we will investigate your claim.
}

Copyright and moral rights for the publications made accessible in the public portal are retained by the authors and/or other copyright owners and it is a condition of accessing publications that users recognise and abide by the legal requirements associated with these

- Users may download and print one copy of any publication from the public portal for the purpose of private study or research.

- You may not further distribute the material or use it for any profit-making activity or commercial gain

If the publication is distributed under the terms of Article $25 f a$ of the Dutch Copyright Act, indicated by the "Taverne" license above, 


\title{
Pulmonary Rehabilitation in the Management of Chronic Obstructive Pulmonary Disease among Asian Indians- Current Status and Moving Forward
}

\author{
Rohini Bhadraa, Shinjini Bhattacharya ${ }^{a}$, George A. D’Souzab, Annemie M. W. J. Schols ${ }^{c}$ (iD, and Sucharita \\ Sambashivaiah ${ }^{d}$ \\ aSt John's Research Institute, St John's Medical College, Bengaluru, India; bepartment of Pulmonary Medicine, St John's Medical College, \\ Bengaluru, India; 'NUTRIM School of Nutrition and Translational Research in Metabolism, Department of Respiratory Medicine, Maastricht \\ University, Maastricht, The Netherlands; ${ }^{d}$ Department of Physiology, St John's Medical College, Bengaluru, India
}

\begin{abstract}
Chronic Obstructive Pulmonary Disease (COPD) is a significant public health concern in India with high prevalence and associated disability, morbidity, mortality. The progression of COPD is not confined to the lungs but includes extrapulmonary involvement that reduces the functional capacity and quality of life. Pulmonary Rehabilitation (PR) is an evidence-based intervention, targeting multiple domains of pulmonary and extrapulmonary manifestations, and therefore, is recommended as an integral part of COPD management. The practical implementation of PR in India is poor. In this review, we have summarized the latest pieces of evidence in support of PR and highlight the challenges and potential solutions for PR implementation in India.
\end{abstract}

\section{ARTICLE HISTORY}

Received 6 May 2021

Accepted 26 July 2021

\section{KEYWORDS}

Exercise; skeletal muscle dysfunction; sarcopenia; functional capacity; tele-rehabilitation

\section{Introduction}

Chronic Obstructive Pulmonary Disease (COPD) is a complex, heterogeneous chronic respiratory disease with systemic manifestation characterized by airway obstruction, dyspnea, fatigue, and systemic inflammation secondary to smoking or inhalation of toxic particles. Nearly $10 \%$ of the global population above the age of 40 years is affected by COPD [1]. In 2016, the WHO Global Burden of Disease Study has reported 251 million cases of COPD globally and more than $90 \%$ of COPD-associated deaths in low- and middle-income countries [2]. COPD alone is responsible for a higher mortality burden in the South Asian region compared to HIV, Malaria and Tuberculosis combined [3]. India, the second most populated country in the world, constituting nearly one-fifth of the world population, is experiencing a marked increase in the burden of respiratory diseases. Demographic, economic, environmental, and lifestyle changes in past decades have remolded the nation's mortality and morbidity determinants; there is a drastic shift from infectious diseases to non-communicable diseases (NCDs) [4]. COPD has been shown to have a mortality rate of $8.7 \%$ in India as per the Global Burden of Diseases, Injuries, and Risk Factors Study (GBD) 2016 [5] and is the second leading cause of death in the country $[5,6]$. It is estimated that India contributes to approximately $20 \%$ of worldwide COPD cases annually [4]. The crude estimate of COPD burden in this country is over 30 million [3]. COPD contributed to $75.6 \%$ of the nation's chronic respiratory disease disability-adjusted life years (DALY) in 2016 [7], In a recent report in economic times, Sundeep Salvi, Director of Chest Research Foundation, Pune, labeled India as the "COPD Capital of the World" [8].

Additionally, the cost of management of COPD is high. In 2011, the estimated economic loss due to COPD in India (₹350 Billion) was higher than the total budget of the Ministry of Health and Family Welfare of India for the year 2010-2011 (approx. ₹251 Billion) [3,9]. This massive disease volume and associated mortality, morbidity, and economic losses in the country calls for revisiting the prevention and management strategies to identify gaps, pitfalls, and opportunities.

COPD management in India primarily concentrates on pharmacological treatment to manage symptoms that are frequently associated with poor compliance. Philip et al, in their recent study, found that about one-third of the patients were non-adherent to prescribed treatment [10]. Most importantly, COPD is a systemic illness that involves extrapulmonary manifestations including weight loss, skeletal muscle dysfunction, cachexia, and osteoporosis [11] often appearing to be clustered. Pharmacological therapies such as bronchodilators and corticosteroids certainly help in the management of the pulmonary pathology but might have a limited role in improving extrapulmonary involvement like the skeletal muscle manifestation and associated loss of physical capacity. Muscle wasting itself may be a potential side effect of corticosteroids used for the management of exacerbations [12]. Pulmonary rehabilitation (PR) is an evidence-based non-pharmacological approach that integrates 
multiple interventions (exercise training, dietary advice and nutritional support, patient education, and psychosocial support) to address the extrapulmonary manifestations of COPD [13]. PR has consistently shown promising results in improving dyspnea, functional capacity, exacerbation frequency, recurrent hospitalization, and quality of life [13-15]. According to the American Thoracic Society, the PR program teaches the patients to be "in charge" of their breathing [14]. Despite well-established benefits, PR programs are extremely underprovided and/or underutilized in developing countries like India. This review focuses on the current state of pulmonary rehabilitation and the challenges in implementing PR programs in India as well as emphasizes the urgent need for the development of a comprehensive rehabilitation program for the well-being of the patients.

\section{Pulmonary rehabilitation: The pressing priority in the management of COPD}

Skeletal muscle dysfunction is an overreaching condition that is associated with the disease progression in COPD and affects the physical capacity and overall quality of life of the patients $[11,16]$. It is caused by loss of muscle mass and oxidative capacity. Unintended weight loss in COPD is often the result of the loss of both skeletal muscle mass and fat mass which may progress and manifest as pulmonary cachexia. Muscle loss in COPD predicts morbidity and mortality independent of airflow obstruction [17] and is associated with higher utilization of health care resources [18]. Indians, in general, are known to possess lesser muscle mass and strength compared to western ethnic groups [19]. The disease-associated pathophysiological alteration of skeletal muscle may further accelerate muscle mass and related function loss. In addition to this, malnutrition which is widely prevalent in developing countries is another important issue that demands attention. $14 \%$ of the total population in India (189.2 million) has been observed to be undernourished as per the Food and Agricultural Organization's 2020 report on "The State of Food Security and Nutrition in the World" [20]. COPD also has a key role in the development of malnutrition among patients because of the decrease in appetite, increased caloric needs because of the work of breathing, chronic inflammatory state, etc. This may further deteriorate lung function, reduce immunity, increase infection risk [21], and catalyze skeletal muscle loss. In a nation where a substantial portion of the population is already undernourished and even the seemingly healthy adults possess a low muscle quality, a chronic disease like COPD can do substantial damage. Hence it is essential to screen all the COPD patients for muscle quality and nutritional status to identify the patient at risk and initiate early rehabilitation so that the grave outcomes can be minimized.

Exercise training serves as the cornerstone of $\mathrm{PR}$ that addresses the vicious cycle of dyspnea, physical inactivity, deconditioning, and isolation [22]. It may, therefore, result in improvement of oxidative capacity and skeletal muscle adaptation depending on the intensity and frequency of exercise. Early initiation of PR can potentially minimize the effect of acute exacerbations on the skeletal muscle and prevent the deterioration of skeletal muscle to a significant extent [23], thus appearing to be an effective strategy to change the course of the disease [24]. Several other studies have demonstrated significant improvement in muscle function and quality of life [25-30], psychosocial wellbeing [31], reduction in mortality, and rate of hospitalization [32] following successful completion of PR. The benefits of PR can be further maximized by introducing supplemental nutrition $[33,34]$. Recent meta-analyses and systematic reviews found that nutritional support in COPD improves the nutritional status among the patients that have been associated with significant improvement in functional capacity, respiratory muscle strength, and quality of life [33]. Nutritional support with PR has the potential to prevent a negative energy balance as well as to prevent or reverse weight loss and muscle wasting [34].

\section{Pulmonary rehabilitation in India- current scenario}

In India, the concept of PR was adopted into COPD care probably in the 1990s in the southern part of India. However, it came into practice at the beginning of the twenty first century [35]. Nevertheless, effective implementation of PR in clinical practice in India is still lacking. Several studies have demonstrated the good clinical outcomes of successfully implemented PR even in a poor resource setting [36-42]. Though limited in number, the results seem promising to recommend its use in India to improve clinical outcomes and facilitate independence in COPD patients (Table 1). For instance, Bhattacharyya et al demonstrated that even a single supervised session of curriculum-based PR which included patient education, bronchial hygiene, and exercise training when practiced by patients, resulted in significant health status improvement after 6 weeks and the benefits lasted for a year, provided, it was reinforced and supervised [36]. It is noteworthy, that indigenous practices such as yoga have also been proven to be beneficial in improving dyspnea and fatigue along with significant improvement in $\mathrm{SpO} 2 \%$ and 6 min walk distance [37]. Multiple studies have evaluated the effectiveness of home-based PR programs and found a favorable outcome to consider home-based PR as an economical but effective alternative [38-40].

PR has been in existence for seven decades and is a recommended mode of managing COPD in most guidelines, yet its implementation in India is in its infancy which is indeed surprising. Only a few isolated clinicians and researchers deliver the benefits of PR to their COPD patients which are primarily located in metropolitan cities. In a country, where a majority of the population resides in the rural areas [43], access to PR therapy by the rural population is extremely important so that all patients are benefited irrespective of their geographical location or social strata. There might be gaps at multiple levels; delay in diagnosis and referral at clinician level, resistance to participate in rehabilitation programs at the patient level, lack of accessibility to PR services, lack of structured policies to manage the disease at the national level. However, given the proven 


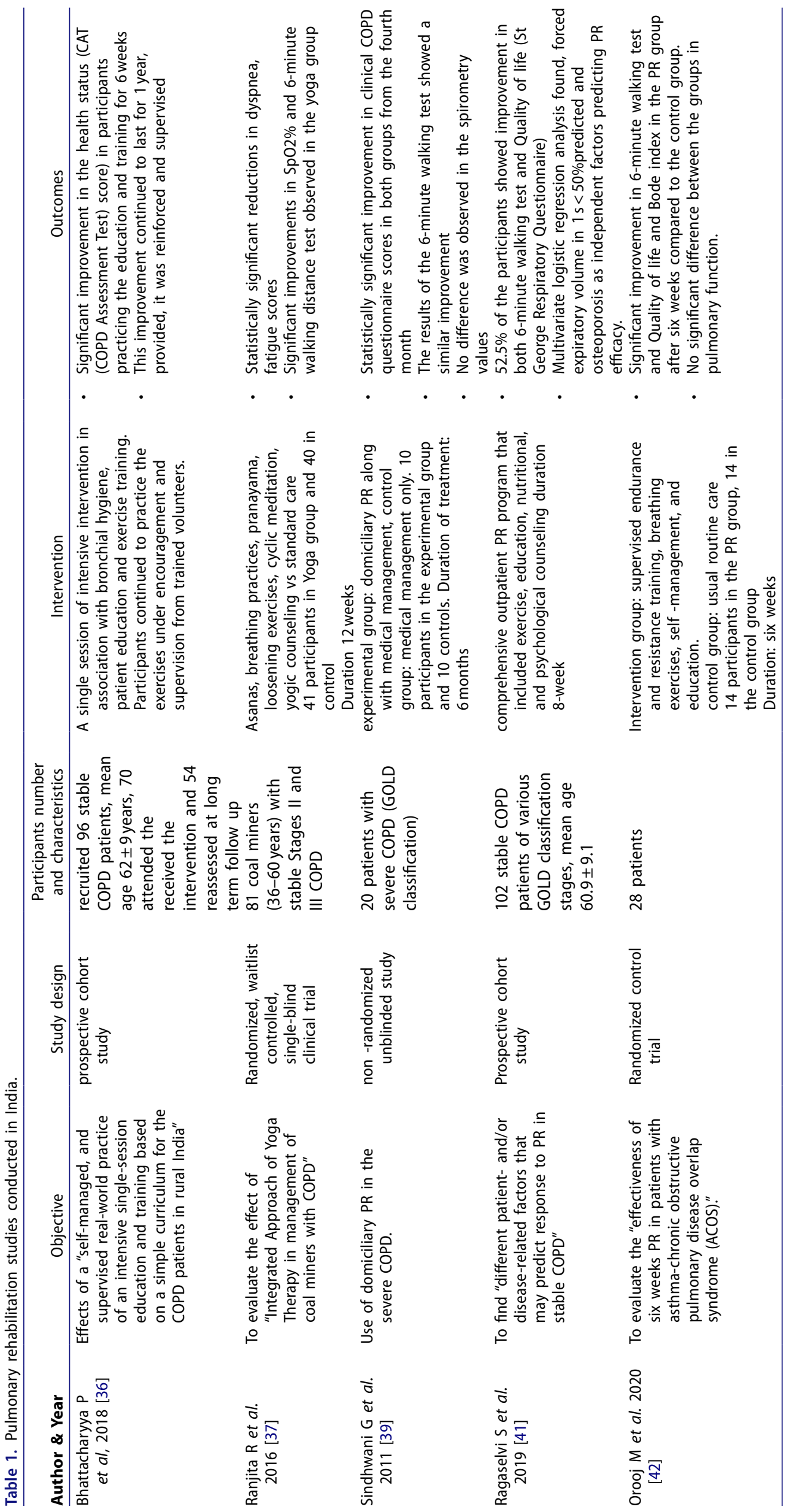


benefits of PR, it needs to be more widely available to reduce the functional burden of disease, associated disabilities, and economic loss caused by COPD.

\section{Challenges of pulmonary rehabilitation programs in India and the way forward}

Translation of PR into clinical practice is not only poor in developing countries like India but also in developed countries. Internationally, the utilization of PR is in only $1-2 \%$ of the total COPD population [44]. This is indeed striking, given the burden of this disease and the observed benefits of PR. Therefore, it is important to understand the reasons for its poor implementation.

The deficit is not only in the management but in the diagnosis and follow-up as well. A great degree of under-diagnosis is still present as spirometry is not performed routinely. A study on the use of spirometry for diagnosis of obstructive airway disease in India demonstrated that as of $2013,72 \%$ of chest physicians, $26 \%$ general physicians, and $12 \%$ general practitioners used spirometry as a diagnostic tool [45]. This can be estimated to be more when comparing rural with the urban population. This is compounded by the lack of public awareness about the disease, its implications, and treatment options [46]. Thakrar et al, reported COPD awareness among Indians to be around $47.8 \%$ and PR awareness to be around $25.1 \%$ [47]. Therefore, diagnosis predominantly takes place at a more advanced stage that limits the potential benefits that could have been achieved through early intervention and treatment. Lack of awareness among healthcare professionals and the community about the beneficial role of PR plays a vital role in the nonavailability of adequate PR facilities in India [48]. According to Kunoor et al, only $54.7 \%$ of healthcare professionals approached by them were aware of PR components [49]. Lack of awareness among the patients also serves as a limitation to the success of PR. According to the respondents in the study conducted by Kunoor et al, the major reasons for referred patients not attending PR programs were inaccessibility of PR centers, demotivation, unavailability of transport, cost, lack of caretakers, and recurrent exacerbations [49].

In India, acquiring the required workforce and associated cost may be an issue. A strong PR program would involve a multidisciplinary team consisting of several trained healthcare personnel working in collaboration $[48,50]$. This entails increased manpower and cost hence increased treatment cost which may not be acceptable or affordable for many patients. In India, the annual mean out-of-pocket expenditure of a patient with COPD has been reported to be between Indian Rupees (INR) 11835.85 to 50805.24, depending on government or private healthcare [51]. It is noteworthy that half of the total out-of-pocket expenditure in the given amount accounted for the hospital stay, followed by the cost associated with drug therapy. Other common treatments such as bronchodilators and oxygen therapy are easily available as well as adequately marketed [44]; the same cannot be said for PR. Interestingly, a study in the
UK has shown the cost-effectiveness (cost per quality-adjusted life year) of PR to be much better than that of bronchodilator therapy $[44,52]$.

To establish a rehabilitation program one of the first criteria is the availability of adequate space and resources such as trained staff and equipment [48]. Developing such a center in India may be a major challenge given the space constraint already existent in hospitals. Additionally, since PR is time-consuming and results take time to appear, hospital authorities prefer to invest existing space and resources in the development of services like intensive care facilities where the returns are faster, and outcomes are quick to appear. In addition, as early detection of COPD is low in India, and the disease is often diagnosed during an acute exacerbation, there appears a greater need for intensive care facilities than PR facilities [48]. Also, the emphasis on curative rather than preventive in most hospital settings is a deterrent. Telerehabilitation may, therefore, be an effective solution to help overcome the constraints in a conventional PR facility. Telerehabilitation is defined as the provision of rehabilitation services with the use of digital technology. It allows the providers to deliver services and monitor the patient remotely via desktop or smartphone and has been suggested as an effective therapy [53]. The main benefit of telerehabilitation is accessibility and feasibility with limited space even in the home environment, easy monitoring, reduction in cost from both the patient as well as the hospital side [54]. Telerehabilitation using exercise instruction videos, educational material, online counseling sessions can help the patients stay motivated throughout the PR program thereby ensuring better compliance and sustainability. Internationally, the validity and reliability of telerehabilitation against conventional rehabilitation programs have been found to be satisfactory [55]. Telerehabilitation appears to be an excellent opportunity for delivering PR services but requires expertise. Considering the insufficient knowledge and implementation of conventional PR already existent in the country, it may not be appropriate to use it as the standard mode of delivery immediately. At this stage, it is important that the health care personnel and caregivers are educated and trained on the concepts of PR to reinforce the development of PR services in the country.

$P R$ is an effective but slow and gradual process that requires specialized infrastructure. If it is to be widely used one will have to educate both doctors and patients of its importance and utility. It also must be advocated to the community. Early diagnosis of COPD and concepts of PR should be included in both UG and PG training of doctors, nurses, and physiotherapists. This requires an elevated level of collaborative engagement among medical professionals, community workers, and the general population. Innovative methods and solutions may be looked at. Telerehabilitation is a promising approach that may be explored but it still requires experimental validation. A multipronged strategy of advocacy, education, and innovation is required if we want to use this effective treatment to manage COPD patients more effectively and reduce the burden of disease. 


\section{Conclusion}

Management of COPD in India is reliant on bronchodilators, corticosteroids, and oxygen therapy. PR has been, time and again, proven to be beneficial in the holistic treatment of COPD and has been established as the standard of care in the management of COPD (in combination with pharmacological treatment). Implementing a protocolized rehabilitation program in a developing country with inadequate resources is indeed challenging. However, the nationwide burden of the disease and associated economic loss with conjoining constraints such as poor muscle quality and high prevalence of malnutrition in the population necessitates the utilization of PR in the country. Moving forward, educating the health care fraternity, and promoting mass awareness is of foremost importance for the success of PR. Telerehabilitation appears to be an attractive mode of delivery but it must be evaluated in developing world setting through appropriate clinical trials.

\section{ORCID}

Annemie M. W. J. Schols (D) http://orcid.org/0000-0001-9878-0428

\section{References}

1. Costa TM, Costa FM, Moreira CA, et al. Sarcopenia in COPD: relationship with COPD severity and prognosis. J Bras Pneumol. 2015;41(5):415-421. DOI:10.1590/S180637132015000000040

2. World Health Organization. Chronic obstructive pulmonary disease (COPD)-factsheet. [accessed 2020 Nov 6]. Available from: https://www.who.int/news-room/fact-sheets/detail/ chronic-obstructive-pulmonary-disease-(copd)

3. Salvi S, Agrawal A. India needs a national COPD prevention and control programme. J Assoc Physicians India. 2012;(60 Suppl):5-7.

4. Bhome $\mathrm{AB}$. COPD in India: Iceberg or volcano?J Thorac Dis. 2012;4(3):298-309. DOI:10.3978/j.issn.2072-1439.2012.03.15

5. Gupta AV, Phatak AG, Patel MU, et al. Effectiveness of a community health worker (CHW) training in monitoring and care of patients with chronic obstructive pulmonary disease (COPD) in rural Gujarat, India. J Family Med Prim Care. 2020;9(4):19101914. DOI:10.4103/jfmpc.jfmpc_1193_19

6. Rajkumar P, Pattabi K, Vadivoo S, et al. A cross-sectional study on prevalence of chronic obstructive pulmonary disease (COPD) in India: rationale and methods. BMJ Open. 2017;7(5):e015211. DOI:10.1136/bmjopen-2016-015211

7. India State-Level Disease Burden Initiative CRD Collaborators. The burden of chronic respiratory diseases and their heterogeneity across the states of India: the global burden of disease study 1990-2016. Lancet Glob Health. 2018;6(12):e1363-e1374.

8. India continues to be the neglected COPD capital of the world. ET Health World. October 03, 2019 [cited 2020 Nov 05]. Available from: https://health.economictimes.indiatimes.com/ news/industry/india-continues-to-be-the-neglected-copd -capital-of-the-world/71426595

9. Murthy KJ, Sastry JG. Economic burden of chronic obstructive pulmonary disease. In: Rao KS, editor. Burden of disease in India. New Delhi (India): National Commission on Macroeconomics and Health; 2005. p. 264-274.

10. Philip A, Mohanan M, Shine M, et al. Assessment of medication adherence barriers in COPD patients in a secondary care teaching hospital. J Drug Delivery Ther. 2020;10(2-s):80-85. DOI:10.22270/jddt.v10i2-s.4013
11. Barnes PJ, Celli BR. Systemic manifestations and comorbidities of COPD. Eur Respir J. 2009;33(5):1165-1185. DOI:10.1183/090 31936.00128008

12. Hasselgren PO, Alamdari N, Aversa Z, et al. Corticosteroids and muscle wasting: role of transcription factors, nuclear cofactors, and hyperacetylation. Curr Opin Clin Nutr Metab Care. 2010;13(4):423-428. DOI:10.1097/MCO.0b013e32833a5107

13. Ries AL, Bauldoff GS, Carlin BW, et al . Pulmonary rehabilitation: joint ACCP/AACVPR evidence-based clinical practice guidelines. Chest. 2007;131(5 Suppl):4S-42S. DOI:10.1378/chest.06-2418

14. Lareau SC, Fahy B. Pulmonary rehabilitation. Am J Res Crit Care Med. 2018;198(10):P19-P20. DOI:10.1164/rccm.19810P19

15. Nici L, ZuWallack RL. Pulmonary rehabilitation: definition, concept, and history. Clin Chest Med. 2014;35(2):279-282. DOI:10.1016/j.ccm.2014.02.008

16. Barreiro E, Jaitovich A. Muscle atrophy in chronic obstructive pulmonary disease: molecular basis and potential therapeutic targets. J Thorac Dis. 2018;10(Suppl 12):S1415-S1424. DOI:10. 21037/jtd.2018.04.168

17. Swallow EB, Reyes D, Hopkinson NS, et al. Quadriceps strength predicts mortality in patients with moderate to severe chronic obstructive pulmonary disease. Thorax. 2007;62(2):115-120. DOI:10.1136/thx.2006.062026

18. Decramer M, Gosselink R, Troosters T, et al. Muscle weakness is related to utilization of health care resources in COPD patients. Eur Respir J. 1997;10(2):417-423. DOI:10.1183/09031936.97.100 20417

19. Lear SA, Kohli S, Bondy GP, et al. Ethnic variation in fat and lean body mass and the association with insulin resistance. J Clin Endocrinol Metab. 2009;94(12):4696-4702. DOI:10.1210/ jc. 2009-1030

20. Hunger in India. 2011-2021 Food Security Foundation India. India Food Banking Network. [cited 2020 Nov 06]. Available from: https://www.indiafoodbanking.org/hunger

21. Dattilo Anne M. Journal of Cardiopulmonary Rehabilitation November-December 1993 - p 387-394. [cited 2020 Nov 06]. Available from: https://journals.lww.com/jcrjournal/ Abstract/1993/11000/Nutrition_An_Essential_Component_of_ Pulmonary.3.aspx

22. Corhay JL, Dang DN, Van Cauwenberge H, et al. Pulmonary rehabilitation and COPD: providing patients a good environment for optimizing therapy. Int J Chron Obstruct Pulmon Dis. 2014;9(1):27-39. DOI:10.2147/COPD.S52012

23. Gayan-Ramirez G. Relevance of nutritional support and early rehabilitation in hospitalized patients with COPD. J Thorac Dis. 2018;10(Suppl 12):S1400-S1414. DOI:10.21037/jtd.2018. 03.167

24. Girdhar A, Agarwal P, Singh A. Pulmonary rehabilitation in chronic obstructive pulmonary disease. In: Sözen H, editor. Cardiorespiratory fitness. IntechOpen; 2018. DOI:10.5772/intechopen. 81742

25. Liao W-h, Chen J-W, Chen $\mathrm{X}$, et al. Impact of resistance training in subjects with COPD: a systematic review and meta-analysis. Respiratory Care. 2015;60(8):1130-1145. DOI:10.4187/respcare. 03598

26. Nyberg A, Carvalho J, Bui KL, et al. Adaptations in limb muscle function following pulmonary rehabilitation in patients with COPD-a review. Rev Port Pneumol. 2016;22(6):342-350. DOI:10.1016/j.rppnen.2016.06.007

27. Grandio G, Baydur A, Yetter G, et al. Pulmonary rehabilitation improves quadriceps muscle strength in patients with chronic respiratory disorders. Chest. 2020;158(4):A2062. DOI:10.1016/j. chest.2020.08.1783

28. Yang J, Lin R, Xu Z, et al. Significance of pulmonary rehabilitation in improving quality of life for subjects with COPD. Respir Care. 2019;64(1):99-107. DOI:10.4187/respcare.06353

29. Ilie A, Crisan A, Stanca P, et al. Effectiveness of pulmonary rehabilitation in improving quality of life in patients with different COPD stages. Balneo Res J. 2020;11:03-08. DOI:10.12680/ balneo.2020.307. 
30. McCarthy B, Casey D, Devane D, et al. Pulmonary rehabilitation for chronic obstructive pulmonary disease. Cochrane Database Syst Rev. 2015;(2):CD003793. DOI:10.1002/14651858.CD003793. pub3

31. Gordon CS, Waller JW, Cook RM, et al. Effect of pulmonary rehabilitation on symptoms of anxiety and depression in COPD: a systematic review and meta-analysis. Chest. 2019;156(1):80-91. DOI:10.1016/j.chest.2019.04.009

32. Ryrsø CK, Godtfredsen NS, Kofod LM, et al. Lower mortality after early supervised pulmonary rehabilitation following COPD-exacerbations: a systematic review and meta-analysis. BMC Pulm Med. 2018;18(1):154. DOI:10.1186/s12890-018-0718-1

33. Collins PF, Elia M, Stratton RJ. Nutritional support and functional capacity in chronic obstructive pulmonary disease: a systematic review and meta-analysis. Respirology. 2013;18(4):616629. DOI: $10.1111 /$ resp. 12070

34. Schols AM. Nutritional and metabolic modulation in chronic obstructive pulmonary disease management. Eur Respir J Suppl. 2003;46:81s-86s. DOI:10.1183/09031936.03.00004611

35. Vaishali K, Sinha MK, Maiya AG, et al. The initial steps in pulmonary rehabilitation: how it all began?Lung India. 2019;36(2):139-141. DOI:10.4103/lungindia.lungindia_101_18

36. Bhattacharyya P, Ghosh R, Saha D, et al. The impact on health status in short- and long-terms of a novel and non-orthodox real-world COPD rehabilitation effort in rural India: an appraisal. Int J Chron Obstruct Pulmon Dis. 2018;13:3313-3319. DOI:10.2147/COPD.S160665

37. Ranjita R, Hankey A, Nagendra HR, et al. Yoga-based pulmonary rehabilitation for the management of dyspnea in coal miners with chronic obstructive pulmonary disease: a randomized controlled trial. J Ayurveda Integr Med. 2016;7(3):158-166. DOI:10.1016/j.jaim.2015.12.001

38. Singh V, Khandelwal DC, Khandelwal R, et al. Pulmonary rehabilitation in patients with chronic obstructive pulmonary disease. Indian J Chest Dis Allied Sci. 2003;45(1):13.

39. Sindhwani G, Verma A, Biswas D, et al. A pilot study on domiciliary pulmonary rehabilitation programme in the management of severe chronic obstructive pulmonary disease. Singapore Med J. 2011;52(9):689-693.

40. Pande A, Singhal P, Kumar R, et al. Effect of home-based pulmonary rehabilitation programme on disability in patients with chronic obstructive pulmonary disease. Indian J Chest Dis Allied Sci. 2005;47(3):217-219.

41. Ragaselvi S, Janmeja AK, Aggarwal D, et al. Predictors of response to pulmonary rehabilitation in stable chronic obstructive pulmonary disease patients: a prospective cohort study. J Postgrad Med. 2019;65(2):101-106.

42. Orooj M, Moiz JA, Mujaddadi A, et al. Effect of pulmonary rehabilitation in patients with asthma COPD overlap syndrome: a randomized control trial. Oman Med J. 2020;35(3):e136. DOI:10.5001/omj.2020.54

43. Rural population (\% of total population) - India. World Bank staff estimates based on the United Nations Population Division's World Urbanization Prospects: 2018 Revision. The World Bank. 2020 [cited $2021 \mathrm{Jul}$ 14]. Available from: https://data.worldbank. org/indicator/SP.RUR.TOTL.ZS?locations=IN

44. Casaburi R. Pulmonary rehabilitation: where we've succeeded and where we've failed. COPD. 2018;15(3):219-222. DOI:10.108 $0 / 15412555.2018 .1503245$

45. Vanjare N, Chhowala $S$, Madas $S$, et al. Use of spirometry among chest physicians and primary care physicians in India. Npj Prim Care Resp Med. 2016;26(1):16036. DOI:10.1038/npjpcrm.2016.36

46. Koul PA. Chronic obstructive pulmonary disease: Indian guidelines and the road ahead. Lung India. 2013;30(3):175-177. DOI:10.4103/0970-2113.116233

47. Thakrar R, Alaparthi GK, Kumar SK, et al. Awareness in patients with COPD about the disease and pulmonary rehabilitation: a survey. Lung India. 2014;31(2):134-138. DOI:10.4103/0970-2113.129837

48. Bansal V, Gaur SN. Challenges of developing a pulmonary rehabilitation programme: Practical aspects with India as a model country. Indian J Chest Dis Allied Sci. 2016;58(2):89-91.

49. Kunoor A, Surendran D, Perathur A, et al. Knowledge and perception towards pulmonary rehabilitation by health care professionals and barriers. Chest. 2020;158(4):A2458. DOI:10.1016/j. chest.2020.09.038

50. Ringbaek TJ, Broendum E, Hemmingsen L, et al. Rehabilitation of patients with chronic obstructive pulmonary disease. Exercise twice a week is not sufficient! . Respir Med. 2000;94(2):150-154. DOI:10.1053/rmed.1999.0704

51. Londhe J, Mudliar K, Powar K, et al. 2019. Direct and indirect costs of COPD treatment in Pune city, India. Eur Res J. 2019;54(Suppl 63):PA1967. DOI:10.1183/13993003.congress-2019. PA1967

52. Zoumot Z, Jordan S, Hopkinson NS. Emphysema: time to say farewell to therapeutic nihilism. Thorax. 2014;69(11):973-975. DOI:10.1136/thoraxjnl-2014-205667

53. Tsai LL, McNamara R, Moddel C, et al. Telerehabilitation in people with chronic obstructive pulmonary disease (COPD): a randomised controlled trial. Eur Respir J. 2016;48(suppl 60):PA2065.

54. Bairapareddy KC, Chandrasekaran B, Agarwal U. Telerehabilitation for chronic obstructive pulmonary disease patients: an underrecognized management in tertiary care. Indian J Palliat Care. 2018;24(4):529-533. DOI:10.4103/IJPC.IJPC_89_18

55. Cox NS, McDonald CF, Alison JA, et al. Telerehabilitation versus traditional Centre-based pulmonary rehabilitation for people with chronic respiratory disease: protocol for a randomised controlled trial. BMC Pulm Med. 2018;18(1):71. DOI:10.1186/s12890018-0646-0 